\title{
Experiment on identical siblings separated at birth: ethical implications for researchers, universities, and archives today
}

\author{
Robert L. Klitzman, ${ }^{1}$ Adam M. Kelmenson ${ }^{2}$
}

'Professor of Psychiatry; Director, Masters of Bioethics Program, Columbia University, New York, New York, USA ${ }^{2}$ Faculty of Medicine, Chinese University of Hong Kong, Hong Kong SAR, Hong Kong

\section{Correspondence to} Dr Robert L. Klitzman, Professor of Psychiatry; Director, Masters of Bioethics Program, Columbia University, New York, NY 10027-6902, USA:

rlk2@columbia.edu

Received 20 November 2019

Revised 4 March 2020

Accepted 10 April 2020

\section{Check for updates}

(c) Author(s) (or their employer(s)) 2020. No commercial re-use. See rights and permissions. Published by BMJ.

To cite: Klitzman RL, Kelmenson AM. J Med Ethics Epub ahead of print: [please include Day Month Year]. doi:10.1136/

medethics-2019-105983

\section{ABSTRACT}

Several films, including Three Identical Strangers, examined ethical problems in an experiment that involved identical siblings who were adopted as infants and separated into different families to examine the effects of nature versus nurture. The study was primarily designed and directed by Dr Peter Neubauer. The experiment, conducted in the 1960's through 1980's, serves as an important cautionary case study, raising several critical and ongoing ethical issues faced by researchers, universities and archives today. The organisation coordinating the study donated the research records to Yale University under the condition that they remain sealed until 2065, and has impeded study participants' full access to research material. This case raises questions of what investigators, their descendants, research ethics committees or institutional review boards (IRBs), universities and archives should do with study records when researchers retire or die-whether universities should accept researchers' donations of archival records that may contain patient or participant data, and if so, under what conditions. This study also poses crucial issues for IRBs - for example, whether researchers themselves or their designates should control all access to study records, particularly if controversy or lawsuits ensue. These questions will become increasingly crucial since the amount of research has burgeoned over recent decades, and investigators, on retirement or death, may want to donate their archives to universities. This experiment thus highlights ethical questions to which researchers, IRBs, universities, healthcare institutions, archivists and libraries should attend.

Recently, two films, Three Identical Strangers ${ }^{1}$ and The Twinning Reaction ${ }^{2}$ brought wide public media attention to ethical questions regarding an experiment that involved separating adopted identical siblings as infants for placement in different families to research the effects of nature versus nurture. Though conducted in the past, the study serves as an important cautionary case study, raising several critical and ongoing ethical issues faced by researchers and universities.

Starting in the 1950s, Dr. Viola Bernard, a New York-based psychiatrist affiliated with Columbia University and Chief Psychiatrist for Louise Wise Services (LWS) adoption agency, felt that twins would fare better psychologically if they were raised apart, and she expressed concerns that adoption of twins posed financial and social burdens to parents, making these children less desirable. ${ }^{3}$ Bernard thus advised LWS to separate such twins who were put up for adoption. ${ }^{1245}$ In the late 1950 's, she mentioned this separation practice to Dr Peter B Neubauer, ${ }^{46}$ Director of the Jewish Board of Guardians' Child Development Center (CDC) and Clinical Psychiatry Professor at New York University. He felt the adoption practice presented an important research opportunity to study questions regarding nature versus nurture. At the direction of Bernard, identical siblings were identified to Neubauer's team, then separated and placed for adoption. During the siblings' time in foster care at LWS, and after they were adopted into homes, Neubauer's team conducted psychological research including film recording, family and play-time observations, interviews and psychological testing. ${ }^{4}$ Some evidence suggests that after the onset of the study, the adoption agency recruited and separated additional siblings for the purposes of increasing the sample size. ${ }^{578}$ LWS appears to be the only agency at the time actively supporting separation. ${ }^{9}$ All biological parents appeared to have had mental illness. Neubauer continued to have research assistants study the siblings through periodic home visits through 1981. Biological parents, adoptive parents and participants were never told the experiment's true purpose (adoptive parents were told only that the children were enrolled in an adoption study) or the fact that identical siblings existed. ${ }^{10}$ Further, Neubauer never published the study's results, ${ }^{1,4}$ raising ethical concerns.

In 1990, presumably at the request of Neubauer, the CDC, now named The Jewish Board of Family and Children's Services (The Jewish Board), donated all documents to Yale University under the condition that they remain sealed until $2065 .{ }^{11}$ In 2000, Kathleen L Kelly, personal assistant and executor of the Bernard Estate after Bernard's death in $1998,{ }^{12}$ similarly donated Bernard's personal archives on the study to Columbia University under a Deed of Gift that requires records to be sealed until $2021 .^{12}$ At least five participants believe that Deeds of Gift sealed access to documents in order to forego reputational damage or legal action against the researchers. ${ }^{113}$ Karen Peart, University Director of External Communications, states that Yale 'accepted the records because the Manuscripts and Archives Library determined that the records held long-term substantive value for the research community. ${ }^{11}$

Since access to documents and data are limited, many details of the study remain unknown. The 1965 National Institute of Child Health and Human Development Research Grant Index lists Neubauer at 'Jewish Board of Guardians, New York, NY' as receiving a grant (001625-01) for 'A longitudinal study of monozygotic twins reared apart'. ${ }^{14}$ But the National Institutes of Health $(\mathrm{NIH})$ reports that it has only financial information about the grant 
and no details about the content of the study itself. Neubauer mentioned a few observations from the study in a trade book, ${ }^{15}$ but provided no details (eg, the experimental design). Neubauer's colleague, Dr Samuel Abrams, Clinical Professor of Psychiatry at New York University Psychoanalytic Institute, references the study, even including some anonymised data with observational descriptions of one set of separated twins, dubbed Amy and Beth, but mentions no study methods or fuller results. ${ }^{16}$ The online Index of Research Files at Yale indicates 11 participants. ${ }^{17}$ Prominent twin researcher Nancy Segal, along with Lawrence Perlman, a research assistant on the project for 10 months in 1967 to 1968 , identify at least 13 participants. ${ }^{45}$ Lori Shinseki, director of the film The Twinning Reaction, identifies 15 participants. ${ }^{210}$ Individuals who screened out at various phases of the study likely account for these discrepancies. One identified set of twins were initially enrolled for study but later excluded from at 6 months of age when their weights started to diverge and they were thought to in fact be dizygotic, not monozygotic. ${ }^{413}$ But how many individuals were thus screened, and separated but not included in the full experiment is also unknown. The exact number of subjects remains unknownstudy participants or screened individuals may not all know that they have a sibling or were separated due to the experiment. While the number of such unwitting participants was not large, ethically, as articulated in the Nuremberg trials and later Belmont Report, informed consent is crucial, but was absent here, and the fact that at least some twins were screened but not included thus constitutes a significant ethical problem.

The Spence-Chapin adoption agency (Spence-Chapin) absorbed the Louise Wise Agency in 2005, along with the latter's records. (Lawrence M Perlman, personal communication, $2019)^{18}$ The records of the screening, including the number of individuals assayed, the nature of the screening and the reasons for exclusion remain held in secret at Spence-Chapin and/or possibly also sealed at Yale. Decisions on family placement may also be housed in the adoption records of Spence-Chapin. ${ }^{3}$

Questions arise as to what should and should not be released or redacted, who should make these decisions and what criteria used to decide which documents to make available, given potential conflicts of interest (COIs) in releasing fuller information, related to actual or possible litigation involved or reputational damage. The Jewish Board did not disclose who reviewed documents and made release decisions-whether lawyers, researchers, executives and so on. Legal counsel at Yale notes that violation of The Board's Deed of Gift could result in litigation, or else dissuade future donors from gifting documents, suggesting that the university may have other COIs in defending the refusal to release documents. ${ }^{11}$ Although we have not been able to review the Deed of Gift with Yale, the Bernard Estate transferred all ownership and copyrights to Columbia University, ${ }^{12}$ but the University continues to seal materials, presumably out of similar concerns for future donations.

Some subjects have tried obtaining their records, but have had to fight The Jewish Board, which has impeded these participants from access. The Jewish Board alleges that all participants are aware of their participation. ${ }^{19}$ Yet, in at least one case, The Jewish Board told individuals that they had not been participants in the study, when in fact they were. Specifically, in 2011, The Jewish Board denied a pair of separated twins (Howard Burack and Doug Rausch) their requests to access the sealed records at Yale, claiming that they were not participants of the study. Eventually, Perlman confirmed that they were participants (personal communication with Perlman, 2019). ${ }^{210}$ Since the wide publicity and national televising in 2018 of the CNN documentary, The Jewish Board has released more material, but up until then had blocked or delayed providing information. Though The Jewish Board claims it has reached out to all participants, ${ }^{19}$ this claim cannot be confirmed, given the variability in the reported number of subjects, and questions remain about the number of individuals screened or separated, but not included in the study. ${ }^{20}$ The Jewish Board might not consider screened individuals to be study participants, in order to diminish the apparent number of people affected by Neubauer's work.

At the time of the study, and in ongoing suppression of documents, The Jewish Board has violated key principles of research ethics. Though Neubauer started his experiment by the early 1960s, he had fled Nazi-occupied Austria, and presumably was thus aware of the Nazi's horrific experiments in concentration camps on twins, the Nuremberg Tribunal in 1945 and the Nuremberg Code established as a result in 1949, dictating that subjects' voluntary consent in research is essential, that studies must have a favourable risk/benefit ratio and that subjects should be able to terminate their participation at any point if they wish. ${ }^{21}$ Subsequent revelations of other egregious research scandals further altered scientific norms and practices. Notably, in 1974, revelations by a journalist about the Tuskegee Syphilis Study prompted Congress to pass the National Research Act in 1974, leading to the Belmont Report in 1979. As the Belmont Report ${ }^{22}$ and Principles of Biomedical Ethics by Beauchamp and Childress articulate, the principles of autonomy and respect for persons require that study participants provide informed consent. ${ }^{23}$ In the case of this study, these crucial principles would necessitate, initially, obtaining consent from the participants' parents, and assent from the participants as children and then as adolescents-all of which the researchers failed to do. The study has undermined principles of non-maleficence ${ }^{23}$ and individual and social beneficence, given that the researchers and agencies involved have refused to provide participants with information that may be helpful to these subjects' personal health and well-being. ${ }^{24}$ Moreover, since the study was never published, and was 'not well organised', ${ }^{4}$ having no clear plan for analysing the data, the potential societal benefits of the study were greatly diminished, thereby placing burdens and risks of participating on the study subjects and their families without any benefit. After 15 years of the study, no one had begun (or been able) to properly compile and analyse the information gathered. ${ }^{4}$ The study design, including separation after siblings had spent up to 6 months together, may have itself caused harm, ${ }^{1625}$ and at least three participants appear to have later committed suicide. ${ }^{10}$ Hence, adoption agencies do not now separate such twins. Yet no systematic follow-up of surviving participants in this study has occurred.

Ethical principles would thus indicate that these participants should be able to obtain copies of their study and their adoption records, and should not have to wait or undergo the costs of legal battles to do so. Providing these records, including all film, audiotapes, data analysis and manuscripts may potentially help these individuals, furthering principles of beneficence and non-maleficence. These individuals may, for instance, be experiencing emotional problems, including suicidal thoughts (given that three of the participants have committed suicide ${ }^{10}$ ), the roots of which they may not understand.

While more paternalistic attitudes toward patients and research subjects were prevalent in the 1950s and early to mid1960s, attitudes have shifted and have become more consumerorientated and patient-centred. Strong reasons have been recently offered for giving patients and research participants access to, for instance, their own genomic data, and 'it is likely that clinical laboratories have, or will soon have, a legal obligation to provide individuals their raw genomic data on request'. ${ }^{26}$ As has been 
articulated recently regarding access to genetics research and big data. 'Asking for access is not the same as asking for ownership or control, just for a reasonable reciprocity'. ${ }^{24}$ The Health Insurance Portability and Accountability Act (HIPAA), enacted in the USA in 1996 to protect identifiable information in medical records ${ }^{27}$, embodies this principle of autonomy-that patients have rights to control access to their data. The NIH has issued guidance, indicating that researchers own rights to data resulting from their grant applications (as opposed to be owned by the $\mathrm{NIH}$ or the researchers' university). But this guidance does not address the issue of participants' rights to their data. ${ }^{28}$

Given the recent public scrutiny, The Jewish Board's document release decisions might be guided by a desire to forego further public backlash. For example, an unpublished manuscript on the study's hypothesis, methods and findings is recently reported to exist, ${ }^{19}$ which might be considered important to participants, but could be damaging for the researchers and adoption agencies involved. The review of documents pertaining to the participants' requests should be comprehensive; the Yale files alone comprise 69 linear feet. ${ }^{29}$ After reaching out to The Jewish Board for access to specific documents, such as the original grant application, Ellen Josem, Chief Legal and Strategy officer for The Jewish Board, reports that The Jewish Board is unaware if the documents exist at Yale (personal communication with The Jewish Board, 2020), raising further questions about the thoroughness of past document review. While the archives, both at Yale and at Columbia, contain a massive amount of material, scholars might be willing to review documents for research under preset privacy guidelines.

The media have mentioned the archives at Yale, ${ }^{12}$ which were partially released to some participants, but it is unknown if The Jewish Board has similarly considered release of Bernard's records at Columbia or Spence-Chapin's files. Those materials might reveal active participation in the study on the part of LWS through increased sibling separation for research purposes, an accusation that has been dismissed but never disproven, ${ }^{19}$ which is concerning given that the information for the Bernard Estate that Columbia library provides on its online search platform (or "finding aid") lists LWS as a co-sponsor of the study, ${ }^{30}$ while personal communications in Bernard's estate reference a joint 'CDC-LWS' study.

Some participants received several heavily-redacted documents-many pages were significantly blackened out-making them difficult to comprehend. ${ }^{12}{ }^{10}$ Yet, The Jewish Board has still not released to participants the study's extensive films or photos (Lawrence M Perlman, personal communication 2019). The specifics of the study's design and hypotheses are similarly unknown.

The Jewish Board claims that releasing additional material to subjects would reveal information about other participants, especially those participants who are not known to the public (personal communication with The Jewish Board, 2020), but information on other subjects could potentially be redacted. Moreover, at least two of these identical siblings mutually granted permission to see each other's records, and other sets of identical siblings might well be willing to do the same. Films and audio files would presumably include only each individual by him or herself, or other individuals in the adoptive family, but not contain multiple participants. What information was redacted from written documents and whether it consists of more than information about the other participants is unknown (since it was redacted).

At least one lawsuit is pending regarding the study, limiting the willingness of some key figures to speak about these issues and the amount of information available. These experimental subjects remain uncertain about several key issues regarding, for instance, how LWS, Neubauer and The Jewish Board chose the families, of which several had previously adopted a child, and were all well-known to the agency-for example, their family makeup and parenting style. The researchers also controlled other variables by placing at least some of the separated sets of identical siblings into families of very different socioeconomic status to see how parenting and other factors might affect them ${ }^{1}{ }^{4}$-for example, intentionally choosing wealthy versus poor families, or adoptive parents who were nurturing versus cold and distant or families with another adoptive child versus single-child homes. To answer these questions, Spence-Chapin could release to participants adoption records, which are known to contain family selection explanations, ${ }^{3}$ but the agency has refused to do so.

Neubauer's former assistant, Natasha Josefowitz, interviewed in Three Identical Strangers, supports the secrecy, arguing that knowledge of participation or the existence of a sibling might be upsetting. ${ }^{19}$ Yet this possibility needs to be balanced against the potential benefits of such disclosure and the principle of autonomy - that participants have certain rights, and the fact that researchers should have obtained informed consent. Each participant, rather than the researcher, should make a decision of whether obtaining the data will or will not be personally upsetting such that the participant does or does not want to obtain it. Similarly, starting in the 1970's, adoption records were partially unsealed, since adoptees were thought to have rights to the information about themselves, especially family health data, even though the initial contracts with biological mothers would have stipulated closed adoptions. Adoption laws and attitudes have similarly changed dramatically. In January 2020, for instance, New York State, citing human rights concerns, granted adoptees over the age of 18 legal right to access full birth records and information provided to the state commissioner, and removed restrictions on disclosing biological sibling information. ${ }^{31}$ It is therefore unclear why Spence-Chapin continues to keep some information sealed. Participants may be unaware of the full scope of information collected (ie, related to screening or participation in the study), and thus not have explicitly petitioned for certain documents that are considered to be outside of the official adoption record.

Yet, Neubauer continued research until 1980, the year that some parents learnt of the study and complained to the adoption agency. This study also underscores how researchers and institutions involved in studies, however well-intentioned, can have COIs that can hinder their recognition of key ethical considerations in their research, and how researchers have duties to publish their findings in order to provide potential benefits to justify risks that may be involved.

Since this study was conducted, oversight of research has improved, but this case serves as an important lesson from the past that can help increase awareness of how researchers can fail to apply principles of research ethics to themselves. Such historical examples remain critical, highlighting ongoing needs for vigilance and self-scrutiny.

This case highlights larger questions of what investigators, their descendants, IRBs and universities should do, when researchers retire or die, with study records collected both before and after HIPAA, and the establishment of IRBs— given that participants or other researchers may now want to access these records. Anecdotally, many researchers, as they transition over several years towards retirement, often enter emeritus status, and must move to smaller offices, and receive less storage and file cabinet space and begin to take their files home for storage in an attic, basement, garage or 
home office. In some cases, they or others may continue to draw on the data, resulting in further papers. Critical questions emerge of whether these investigators or their families should arrange, on researcher's death, to donate these files to libraries, and if so, under what terms?

Even more importantly for institutional policy, universities face dilemmas of whether to accept such donations of archival records that may contain patient or subject data, and if so, under what conditions. Undoubtedly, these questions will become increasingly important since, over the past several decades, the amount of research has burgeoned, and the investigators involved will increasingly be retiring or dying and may wish to donate their archives to universities. Yale and Columbia do not want to break deeds of gift to release these records to participants because doing so might deter future donors of other archives. ${ }^{11}$ Yet, this case highlights why universities should proceed very cautiously in considering whether to accept such records, especially under terms such as those that The Jewish Board and Bernard stipulated-for example, that the records be sealed to patients or participants for years except with The Jewish Board's permission, given that the donor may have COIs in releasing them. The Jewish Board has apparently refused to provide access to any researchers, including the authors of this paper. Similarly, ethical issues have arisen granting access to well-known individuals such as Franklin Roosevelt ${ }^{32}$ and Sigmund Freud, ${ }^{33}$ when family members of these individuals want to restrict access due to potentially bad publicity or damaging information in the archives, creating COIs on the part of owners of the material. ${ }^{34}$ Yet, regarding the Twin Study, the issues concern access by individuals about information regarding themselves, particularly documentation of their own behaviour.

The rights to data ownership and access are increasingly critical, especially with the emergence of biobanks and genomic databases that accumulate massive amounts of information. HIPAA embodies the principles of autonomy and of individuals' rights to have some control over their health data. ${ }^{35}$ Federal guidelines indicate that publicly-funded data used in publications are accessible under the Freedom of Information Act. ${ }^{36}$ IRBs typically determine how data ought to be stored, accessed and under what conditions. However, in cases of research in the 1950's and 1960's, which may have lacked contemporary IRB oversight, issues of access can pose challenges. Some critics have argued that IRB regulations, developed with a focus on biomedical research, should not be applied to psychosocial research that is minimal risk. But the current study raises significant mental health risks, including suicide, and thus poses more than minimal risk, warranting the application of IRB considerations. ${ }^{37}$

Though The Jewish Board claims that participants have had access to those portions of the data that pertain to them, redactions performed render many documents unreadable. Respect for privacy and confidentiality is ethically important, though. HIPAA applies to data collected in the past. ${ }^{38}$ Going forward, researchers and the IRB should clarify ownership and classification of these types of materials at the time of study recruitment and conduct, and later archiving. ${ }^{39}$

Participants have rights to access other potentially helpful portions of the secret unpublished documents, including manuscripts, methods and research procedures. The principles of beneficence and non-maleficence dictate that access is important, especially if information contained at Yale or elsewhere can help alleviate harms caused by study participation. The issue of access to non-published, non-reviewed manuscripts remains an important question for institutions housing publicly-funded research data. Given that subjects bear the risk of research participation, failure on the part of the primary investigator to follow through with publishing should not impede the participants' ability to access results, or be made aware of the study's findings. The public should also be able to access the knowledge gained from projects funded by government agencies to uphold confidence in future research activities paid for by tax dollars.

The Association of College Research Libraries, a division of the American Library Association, has established 'Standards for Libraries in Higher Education' that state, for instance, that 'Libraries advance professional values of intellectual freedom, intellectual property rights and values' and 'privacy and confidentiality' of library users, and 'supports academic integrity and deters plagiarism through policy and education. ${ }^{40}$ But, as Neubauer's study indicates, the applications of these values can at times be complex and/or conflict; and these Standards do not at all mention issues regarding patient and study participant data. It is further unclear how universities should view archived records in the face of ever-changing research guidelines. Gifts given under past laws might not fall into clear categories of research with explicit data access policies.

These Standards protect the privacy of library users (ie, preventing third parties from knowing what books a particular individual has borrowed) but the question here is different-regarding the privacy and confidentiality of individuals mentioned in archival records. Universities and their libraries and relevant professional associations should thus carefully review any guidelines they have concerning such archival donations, to avoid such problems in the future. This case highlights questions regarding under what conditions, if any, study records be open to other researchers. Researchers or organisations that donate subjects' records to an institution should make arrangements for these participants to have access to them, and libraries accepting gifts from organisations or healthcare providers should check whether these archives contain patients' or research participants' records and, if so, seek to ensure that such arrangements have been made. Otherwise, the libraries themselves may be complicit in furthering questionable ethical practices. Libraries should check whether the archives contain patient and/or study participant data, where these were collected (whether pre-HIPAA or post-HIPAA) and what the informed consent, if any, stated about future use.

Libraries themselves, however, may face COIs in receiving such gifts, wanting to accept donations, adding volume and prestige to their holdings. Archives of well-known researchers, authors and scholars can be valuable, but libraries may not recognise needs to examine key ethical issues involved, concerning the potential rights of patients or research participants whose records are included. Scholars seeking access to these records should sign non-disclosure agreements that they will not divulge any identifying information. Use of such records may require notification of an appropriate IRB (as in retrospective reviews of medical charts). This case, indicates, too, that researchers' should seek, if possible, to avoid having more than one participant's records in the same document in ways that would impede the ability of one subject to obtain her records if she wishes. Before accepting records, universities also need to perform due diligence.

This study also poses crucial questions for IRBs-for example, whether researchers themselves should control all access to study records, especially if the experiment becomes the subject of lawsuits or in violation of future research guidelines, what should happen to study records after the researcher(s) die, whether institutions should take responsibility for control of the records, and if so, when and under what conditions and what if institutions being sued also control study participants' access 
to the archive. Arguably, IRBs and their institutions should develop policies concerning future and ongoing access to study records, especially given the increasingly common use of electronic, as opposed to physical paper records. While IRBs may want to request that investigators destroy research records after a set period of years, doing so may in fact significantly diminish the potential broad scientific and social benefits of the study conducted. Researchers in the future might analyse past data in new and productive ways, shedding vital light on new research questions. IRBs should require that researchers stipulate what will happen in the long-term to these study records. Such arrangements increasingly arise and are addressed regarding biobanks, but not for other studies that may be collecting descriptive qualitative and quantitative physical or mental health or psychological data.

Though conducted in the past, this experiment raises ethical questions and concerns to which not only the general public, but also researchers, IRBs, healthcare institutions, universities and libraries now need to attend. Historical examples of a researcher's past unethical behaviour that he or she thought was acceptable are important as cautionary tales, illustrating the nature of these oversights, and how ethical violations can occur despite the existence of past scandals, such as the Nazi experiments and Tuskegee. Such past wrongs are worthy of ongoing attention, given that many researchers continue to overlook or downplay ethical considerations in research conduct.

\section{Twitter Robert L. Klitzman @RobertKlitzman}

Acknowledgements The authors would like to thank Lundyn Davis, Jiseop Kim and especially Patricia Contino for their assistance with the preparation of this manuscript.

Contributors The authors are solely responsible for conception of the research, the acquisition, analysis and/or interpretation of data and the drafting, revising and final version of this manuscript.

Funding The authors have not declared a specific grant for this research from any funding agency in the public, commercial or not-for-profit sectors.

Competing interests None declared.

Patient consent for publication Not required.

Provenance and peer review Not commissioned; externally peer reviewed.

\section{REFERENCES}

1 Three Identical Strangers. USA: CNN films, Raw TV 2018.

2 The Twinning Reaction. USA: fire horse pictures 2017.

3 Wright L. Double mystery. The New Yorker [cited 21 Feb 2020], 1995. Available: https://www.newyorker.com/magazine/1995/08/07/doublemystery?reload

4 Perlman LM, Segal NL. Memories of the child development center study of adopted monozygotic twins reared apart: an unfulfilled promise. Twin Res Hum Genet 2005:8(3):271-81.

5 Segal NL. Commentary: more thoughts on the child development center twin study. Twin Res Hum Genet 2005;8(3):276-81.

6 Segal NL. A possible twin: the 1960s twin study revisited/twin research: twin-to-twin heart transplantation; distinguishing monozygotic twins; twin conceptions via oocyte donation; factors affecting craniofacial traits/In the media: triplet delivery in the UK; conjoined twins and the concept of self; Colombian twin trainers; skin grafting to save an identical co-twin; lack of physical flaws in Dolly the cloned sheep; possible conjoined twins of opposite-sex; passing of the remaining twin from the world's longest separated pair. Twin Res Hum Genet 2018:21(2):155-62.

7 Brown FG. Letter to Viola Bernard from Florence G. Brown. New York, NY: Viola Wertheim Bernard Papers, Archives \& Special Collections, Columbia University Health Sciences Library, Series 5.4, 1961.

8 Brown FG. Letter to Viola Bernard from Florence G. Brown. New York, NY: Viola Wertheim Bernard Papers, Archives \& Special Collections, Columbia University Health Sciences Librarary, Series 5.4, 1965.

9 Kelmenson AM, Wilets I. Historical practice of separating twins at birth. JAMA 2019:322(18)

10 Paparella A, Strauss EM, Effron L, et al. Twins Make Astonishing Discovery that They Were Separated Shortly After Birth and Then Part of a Secret Study. ABC News
[Internet] [cited 21 Feb 2020], 2018. Available: https://abcnews.go.com/US/twinsmake-astonishing-discovery-separated-birth-partsecret/story?id=53593943

11 McCormack W. Records from Controversial Twin Study Sealed at Yale Until 2065. Yale Daily News [Internet] [cited 21 Feb 2020], 2018. Available: https://yaledailynews.com/ blog/2018/10/01/records-from-controversial-twin-studysealed-at-yale-until-2065/

12 Kelly KL, Novak SE. Finding Aid [Internet]. Viola Wertheim Bernard Papers, Archives \& Special Collections, Columbia University Health Sciences Library. New York, NY; 2003 [cited 24 Feb 2020]. Available: https://library archives.cumc.columbia. edu/finding-aid/viola-wertheim-bernard-papers-1918-2000. Available from: https://library-archives.cumc.columbia.edu/finding-aid/viola-wertheim bernardpapers-1918-2000

13 Bernstein P. Elyse S. Identical strangers. New York: Random House, 2007.

14 National Institutes of Health. Research grant index: fiscal year 1965. Vol 2. Bethesda, MD: Division of Research Grants, 1965:1656.

15 Neubauer PB, Neubauer A. Nature's Thumbprint. Reading. MA: Addison-Wesley Publishing Company, 1990.

16 Abrams S. Disposition and the environment. Psychoanal Study Child 1986:41:41-60.

17 Yale.University Manuscripts and Archives. Guide to the Adopotion Study Records of the Child Development Center [Internet]. New Haven, CT; [cited 24 Feb 2020], 2004. Available: http://ead-pdfs.library.yale.edu/3434.pdf

18 Dickter A. Home found for Louise Wise records New York Jewish Week [Internet] [cited 21 Feb 2020], 2005. Available: https://jewishweek.timesofisrael.com/home-found-forlouise-wise-records/

19 Hoffman L, Oppenheim L. Three identical strangers and the twinning reaction clarifying history and lessons for today from peter Neubauer's twins study. JAMA 2019;322(1):10-12.

20 Perlman L. Comment on Three Identical Strangers and The Twinning Reaction clarifying history and lessons for today from Peter Neubauer's Twins Study. JAMA [21 Feb 2020], 2019. Available: https://jamanetwork.com/journals/jama/article-abstract/ 2737146

21 The Nuremberg Code. Trials of war criminals before the Nuremberg military tribunals under control Council law. Washington, D.C: U.S. Government Printing Office, 1949: 2. 181-2.

22 The National Commission for the protection of human subjects of biomedical and behavioral research. The Belmont report: ethical principles and guidelines for the protection of human subjects of research. available. Available: https://www.hhs.gov/ ohrp/regulations-and policy/belmont report/index.html [Accessed 21 Feb 2020].

23 Beauchamp TL, Childress JF. Principles of biomedical ethics. 8th edn. New York: Oxford University Press, 2019

24 Nelson S. Geneticists should offer data to participants. Nature 2016;539(7627):7.

25 Segal N. Twin Mythconceptions: false beliefs, fables, and facts about twins. Cambridge, MA: Academic Press, 2017.

26 Thorogood A, Bobe J, Prainsack B, et al. APPLaUD: access for patients and participants to individual level uninterpreted genomic data. Hum Genomics 2018;12(1):7.

27 U.S. Department of Health \& Human Services. The HIPAA privacy rule. content last reviewed, 2016. Available: https://www.hhs.gov/hipaa/index.html [Accessed 21 Feb 2020].

28 National Institutes of Health. NIH grants policy statement: 8.2.1 rights in data (publication and Copyrighting), revised, 2019. Available: https://grants.nih.gov/ grants/policy/nihgps/html5/section 8/8.2.1 rights_in_data publi ation_and copyrighting_.htm [Accessed 26 Feb 2020].

29 Archives at Yale. Adoption Study records of The Child Development Center. Call Number: MS 1585 [Internet]. New Haven, CT [cited 24 Feb 2020], 2004. Available: https://archives.yale.edu/repositories/12/resources/3434

30 Augustus C. Long Health Sciences Library of Columbia University. Finding aid [Internet]. Viola Wertheim Bernard Papers, Archives \& Special Collections, Columbia University Health Sciences Library. New York, NY; 2020 [cited 24 Feb 2020]. Available: https://library-archives.cumc.columbia.edu/sites/default/files/findingaids/Bernard\% 20finding\%20aid\%20complete\%20web\%20version_2.pdf

31 Senate Bill S2492A: AN ACT to amend the domestic relations law and the public health law, in relation to access to birth records by adoptees, 2020 (State of New York) [Internet]. Available: https://www.nysenate.gov/legislation/bills/2019/s2492 [Accessed 2 Mar 2020].

32 Koch CM. A new FDR emerges. Prologue Magazine 2006:38(4).

33 Malcom J. In the freud archives. New York: New York Review Books, 2002.

34 Danielson ES. The ethical Archivist. Chicago: Society of American Archivists, 2010.

35 Borgman CL. Open data, grey data, and stewardship: universities at the privacy frontier. Berkeley Technol Law J 2018:33:365-412.

36 United States Department of Justice. FOIA.gov. Available: https://www.foia.gov/ [Accessed 26 Feb 2020].

37 Schrag ZM. Ethical imperialism: institutional review boards and the social sciences, 1965- 2009. Baltimore: Johns Hopkins University Press, 2017.

38 Lawrence SC. Access anxiety: HIPAA and historical research. J Hist Med Allied Sci 2007:62(4):422-60.

39 Whorley TM. The tuskegee syphilis study: access and control over controversial records. Pittsburgh: University of Pittsburgh, 2006.

40 The American Library Association. Standards for libraries in higher education. available. Available: http://www.ala.org/tools/guidelines/standardsguidelines [Accessed 21 Feb 2020]. 